\title{
Role of Endometriosis in Infertility and Embryonic Loss: More than Anatomical Reasons
}

\author{
Luz Angela Torres-de la Roche, Hugo Verhoeven and Rudy Leon De Wilde* \\ Clinic of Gynecology, Obstetrics and Gynecological Oncology, University Hospital for Gynecology, Pius-Hospital, Medical Campus University of Oldenburg, \\ Germany
}

Submission: March 06, 2017; Published: March 21, 2017

*Corresponding author: Rudy Leon De Wilde, MD PhD, Clinic of Gynecology, Obstetrics and Gynecological Oncology, University Hospital for Gynecology, Pius-Hospital, Medical Campus University of Oldenburg, Germany, Tel: +49-441-229-1500; Fax: +49441229-1525;

Email: rudy-leon.dewilde@pius-hospital.de

\section{Mini Review}

The association between endometriosis and infertility is widely recognized, but several studies demonstrate that endometriosis also affects pregnancy rates in different ways other than anatomical distortion of internal reproductive organs; however the evoking mechanisms are complex. In mild to advanced stages of disease, peritoneal adhesions, tubal obstruction, destruction of ovarian tissue or distortion of the uterine wall are evident originating factors of infertility or miscarriage. In contrast, in $17 \%$ of all cases of endometriosis, the reason of infertility is not clear [1], especially in women less than 35 years-old, who have a 2-fold increased risk of unexplained infertility $(\mathrm{HR}=2.12,95 \% \mathrm{CI}=1.76-2.56)$ [2], although miscarriage rate after ICSI is not age dependent $(<35$ years-old vs.> 35 years-old women; OR 0,4; $95 \%$ CI 0,1-2,1) [3]. The underlying abnormalities could explain the modest pregnancy rates achieved by currently available medical and surgical treatments, estimated in $52.9-83 \%$ in mild disease and $0-6,7 \%$ insevere disease [1].

Some of the known pathophysiologic factors implied in endometriosis-associated infertility are irreversible (Table 1). They generate functional and structural abnormalities of the hypothalamic-pituitary-ovary-endometrium axis, which in turn lead to retardation of sperm, oocyte and blastocyst transport, alteration of endometrial receptivity and, finally, embryonic loss.

Table 1: Proposed mechanisms of infertility and embryonic loss associated with endometriosis.

\begin{tabular}{|c|c|}
\hline Mechanism & Effect \\
\hline \multirow{4}{*}{ Pituitary-ovarian axis dysfunction } & Altered feedback pathways. \\
\hline & Abnormal cyclic changes in the ovary. \\
\hline & Impaired folliculogenesis. \\
\hline & Poor quality oocytes. \\
\hline Immunological alterations & Alterations in humoral and cell-mediated immunity during luteal phase. \\
\hline \multirow{4}{*}{ Altered peritoneal milieu } & Elevated level of prostaglandins, haptoglobin, cytokines, cellular remodeling enzymes, growth factors. \\
\hline & Sperm dysfunction. \\
\hline & Impaired interaction sperm-endosalpinx epithelium. \\
\hline & Impaired fertilization. \\
\hline \multirow{2}{*}{ Genetic mutations } & Endometrial cells polymorphisms. \\
\hline & Less uterine receptivity. \\
\hline \multirow{5}{*}{ Abnormal uterine receptivity } & Altered steroid hormone pathways. \\
\hline & Decreased or absent expression of implantation regulators and biomarkers. \\
\hline & Delayed blastocyst hatching. \\
\hline & Implantation failure. \\
\hline & Poor quality embryo development \\
\hline
\end{tabular}


Hormonal dysfunction in endometriosis includes [4,5]: extended follicular phase with aberrant patterns of LH-secretion, lower levels of circulating estrogen, androgen and progesterone, and increased intrafollicuaractivin, cytokines and growth factors. This in turn induces premature apoptosis of cumulus cells, alteration of the morphology, maturation and liberation of oocytes, and impairsoocyte fertilization potential. At ultrasound, impairment of follicular growth and low dominant follicle size could be observed. It is also possible to observe trapped oocytes in a luteinizing corpus hemorragicum as a signal of anovulation and altered corpus luteum development, defined as luteinized unruptured follicle syndrome (LUFs).

The local immunologic alteration induced by endometriosis results in an inappropriate milieu for sperm, oocytes, embryo development and uterine receptivity [5]. This milieu is characterized by a high concentration of inflammatory cytokines, oxidative stress products and reactive oxygen species (ROS). These substances affect spermatozoa membrane, leading to an impaired sperm function or rupture, including abnormal spermendosalpinx and sperm-oocyte interaction, low number of free spermatozoa in tubal ampulla, and loss of sperm fertilization potential.

Women with endometriosis also have six-times more nuclear and cytoplasmic aberrations than other women and have been associated with disease severity [6]. These aberrations include polymorphisms, dysregulated micro-RNAs and epigenetic factors. Such factors are able to induce DNA hypomethylation with subsequent alteration of endometrial receptivity mediators and implantation failure [7].

Defects in blastocyst implantation could result due to altered hormonal levels, embryo anomalies orprogesterone-target genes dysregulation [7]. The last leads to a local progesterone resistance and to an inhospitable environment, which in turn impairs blastocyst implantation. This environment is characterized by a decreased or absent expression of implantation and regulators markers of endometrial receptivity, such as integrins, glycodelin A, leukemia inhibitory factor, osteopontin and lysophosphatidic acid receptor. Although hormone and inflammatory marker levels, and uterine cavity anatomy can easily be studied, there is insufficient evidence to recommend an appropriate assessment of endometrial receptivity.

Some studies report that progesterone supplementation and endometrial biopsy may improve endometrial receptivity and pregnancy rates, especially in IVF-embryo transfer cycles [8]. However, the analysis of published evidence is difficult given the quality of the studies and the diversity of proposed treatments, especially those involving assisted- reproductive techniques. Progesterone administration for luteal phase support in embryo transfer protocols is effective when given on the day or the day- after oocyte pick-up (OR 1.87; 95\% CI 1.13 to 3.08). On the other hand, increased endometrial implantation competency after endometrial biopsy are based on endometrial wound healing mechanisms, including secretion of cytokines and growth factors accompanied of stem cells recruitment, which are free of epigeneticdefects, favoring embryo implantation. Treatments with not conclusive efficacy are systemic administration of heparin, aspirin, prednisone, immunoglobulins or recombinant follicle-stimulant hormones. Future therapies involving immunomodulators or hormonal suppressive therapies could be useful to improve fertility and pregnancy rates [9].

\section{Conclusion}

As physicians and gynecologists, the better we understand the underlying causes of infertility, failure of uterine receptivity and impaired embryonic implantation associated to endometriosis, the more appropriate and secured therapies we can provide, although many of these pathophysiological mechanisms are right now not influenceable. Therefore more research is needed to design specific therapies capable of modulating the changeable ones, to improve fertility rates, and to reduce embryonic loss rates, especially when we are facing patients undergoing assisted-reproductive treatments.

\section{References}

1. Johnson NP, Proctor M, Farquhar (2003) Gaps in the evidence for fertility treatment. Analysis of the Cochrane Menstrual Disorders and Subfertility Group. Hum Rep 18(5): 947-954.

2. Prescott J, Farland LV, Tobias DK, Gaskins AJ, Spiegelman D, et al. (2016) A prospective cohort study of endometriosis and subsequent risk of infertility. Hum Reprod 31(7): 1475-1482.

3. Bahceci M, Ulug U (2005) Does underlying infertility aetiology impact on first trimester miscarriage rate following ICSI? A preliminary report from 1244 singleton gestations. Hum Reprod 20(3): 717-721.

4. Stilley JA, Birt JA, Sharpe-Timms KL (2012) Cellular and molecular basis for endometriosis-associated infertility. Cell Tissue Res 349(3): 849-862.

5. Gupta S, Goldberg JM, Aziz N, Goldberg E, Krajcir N, et al. (2008) Pathogenic mechanisms in endometriosis-associated infertility. Fertil Steril 90(2): 247-257.

6. Tomassetti C, Meuleman C, Pexsters A, Mihalyi A, Kyama C, et al. (2006) Endometriosis, recurrent miscarriage and implantation failure: Is there an immunological link? Reprod Bio Medicine Online 13(1):58-64.

7. Cakmak H, Taylor HS (2011) Implantation failure: molecular mechanisms and clinical treatment. Hum Reprod Update 17(2): 242253.

8. Glujovsky D, Pesce R, Fiszbajn G, Sueldo C, Hart RJ, et al. (2010) Endometrial preparation for women undergoing embryo transfer with frozen embryos or embryos derived from donor oocytes. Cochrane Database of Systematic Reviews 1: CD006359.

9. Brown J, Farquhar C (2014) Endometriosis: an overview of Cochrane Reviews. Cochrane Database of Systematic Reviews 3: CD009590. 
(C) (i) This work is licensed under Creative DOI: $10.19080 / J G W H .2017 .03 .555612$
Your next submission with Juniper Publishers will reach you the below assets

- Quality Editorial service

- Swift Peer Review

- Reprints availability

- E-prints Service

- Manuscript Podcast for convenient understanding

- Global attainment for your research

- Manuscript accessibility in different formats

( Pdf, E-pub, Full Text, Audio)

- Unceasing customer service

Track the below URL for one-step submission https://juniperpublishers.com/online-submission.php 